\title{
Normas de presentación
}

\section{Alcance y política editorial}

CUHSO es una publicación semestral de la Facultad de Ciencias Sociales de la Universidad Católica de Temuco. Recibe artículos inéditos en el campo de las ciencias sociales y las humanidades, en especial en las líneas disciplinares de la facultad, en ámbitos como relaciones interétnicas, derechos humanos, desarrollo social y cultural, interdisciplina, marginalidad y exclusión social.

Esta revista se atiene a los principios del acceso abierto definidos por la Budapest Open Access Initiative (BOAI: http://legacy.earlham.edu/ peters/fos/ boaifaq.htm\#openaccess).

\section{Tipos de manuscritos recibidos}

- Artículos originales que den cuenta de avances o resultados de investigaciones empíricas. Serán sometidos a proceso de revisión por pares. Los manuscritos deben tener entre 4 mil y ro mil palabras.

- Artículos teóricos y ensayos originales sobre tópicos específicos de las ciencias sociales y humanidades. Serán sometidos a proceso de revisión por pares. Los manuscritos deben tener entre 8 mil y 22 mil palabras.

- Documentos y testimonios que poseen valor en cuanto material empírico o teórico para las ciencias sociales y humanidades, en particular a nivel regional, la estructura de presentación es libre. Estas contribuciones serán sometidas al Comité Editorial, que decide sobre su publicación. Deben tener una extensión entre I.000 y 2.000 palabras.

- Reseñas de obras en que se comenten publicaciones recientes y relevantes de las ciencias sociales y humanidades. La estructura de presentación es libre. Estos escritos son sometidos al Comité Editorial, que decide sobre su publicación. Deben tener una extensión entre I.000 y 2.000 palabras. 
- Los manuscritos presentados a CUHSO deben ser originales y los autores se comprometen a no presentarlos a otras publicaciones al mismo tiempo.

- Se aceptan manuscritos en francés, inglés, portugués y español de investigadores de cualquier parte del mundo.

\section{Presentación del manuscrito}

Los manuscritos serán enviados a CUHSO a través de su portal (<www.cuhso. cl>) siguiendo las indicaciones para registro de autores ahí establecidas. Los artículos serán sometidos a un proceso de revisión de doble ciego a partir del cual pueden ser rechazados, aprobados con modificaciones o aprobados. Los autores con artículos aprobados con modificaciones y aprobados, se comprometen a efectuar las correcciones de contenido, forma y estilo en los plazos solicitados por CUHSO.

- Los manuscritos enviados deben presentarse en un formato de procesador de texto compatible con Word.

- Cuando corresponda, los autores son responsables de presentar elementos gráficos de calidad y tener en cuenta que la versión impresa de $\mathrm{CUH}$ $S O$ se publica en blanco y negro. Debe indicarse el lugar exacto donde el gráfico se sitúa en el manuscrito. Gráficos, tablas y diagramas deben ser presentados utilizando las herramientas de diseño de un procesador de texto o deben adjuntarse al envío en formato Excel. Las imágenes deben enviarse en formato jpg y en alta resolución.

- Los manuscritos deben ser presentados en letra Times New Roman, tamaño número I2, a doble espacio.

- Todos los tipos de artículos deben incluir una portadilla con el título del manuscrito. En el caso del texto para revisión, debe ser entregado en una versión anónima; aunque en la versión aprobada o aprobada con modificaciones se debe indicar nombre del/los autor/es, correo electrónico, filiación institucional y un breve resumen biográfico.

- El documento presentado a evaluación no debe contener ninguna referencia al/los autor/es, deben ser borrados los datos de firma digital del artículo, así como cualquier referencia como la autocita, por ejemplo, "como discutió el autor», "como expresé en otro momento», etcétera. Se pueden citar a sí mismos en tercera persona. 
- En la siguiente página debe escribirse un resumen de hasta 300 palabras, e incluir hasta cuatro palabras claves. Resumen y palabras claves deben ser presentados en español (una versión en inglés debe incluirse en la versión aprobada o aprobada con modificaciones).

\section{Citación y referencias}

El sistema de citas y referencias de CUHSO están inspirado en las normas APA y está adaptado a las normas propias del castellano. Los siguientes son algunos ejemplos de citación al interior del texto:

- Trabajo de un solo autor: «Pérez (2000)», «como señala Pérez (2000)», «en el 2000 Pérez señaló».

- Obras diferentes de un mismo autor y año deben diferenciarse con letras ordenadas alfabéticamente a continuación de la fecha: Ramírez (2009a), Ramírez (2009b).

- Si un trabajo tiene dos autores deben ser nombrados los dos siguiendo las mismas normas de cita del primer punto.

- Cuando son tres o más autores, cítelos a todos la primera vez y si es necesario citarlos nuevamente, mencione al primer autor seguido de la expresión «y otros».

- Cuando cite a una organización, utilice el nombre completo y entre paréntesis la abreviación; en las siguientes citas, sólo utilice la abreviación.

- Citas textuales de menos de 40 palabras se colocan en el mismo texto entre comillas. Citas de más de 40 palabras se inician en párrafo aparte, con una tabulación adicional de $(\mathrm{I}, 5 \mathrm{~cm})$.

- En las citas textuales indique siempre el año de publicación y número de página: Pérez, 2010: 68.

- En el caso que una obra tenga Digital Object Identifier (DOI), éste debe incluirse en el listado de referencias. Cuando esté disponible el enlace digital de la obra es recomendable incorporarlo. Los siguientes son algunos ejemplos en que los documentos deben aparecer en el listado de referencias. 


\section{Artículos}

- Bengoa, José (20I2). «La economía comunal mapuche». CUHSO, I (I): 43-66. Doi: I0.7770/cuhso-VINi-arti39.

- Dans, Enrique (20I2). «El triste resultado de intentar poner puertas al campo». El Blog de Enrique Dans, 2 de mayo. Disponible en <http:// www.enriquedans.com/20 I 2/05/el-triste-resultado-de-intentar-ponerpuertas-al-campo.html>.

Libros

- Stiglitz, Joseph (2002). El malestar de la globalización. Buenos Aires: Taurus.

- Sartori, Giovani y Leonardo Morlino (eds.) (1996). La comparación en las ciencias sociales. Madrid: Alianza.

Capítulos de libro

- Cimoli, Mario y Annalisa Primi (2008). «Capítulo I. Propiedad intelectual y desarrollo: una interpretación de los (nuevos) mercados del conocimiento». En José Martínez (ed.), Generación y protección del conocimiento: propiedad intelectual, innovación y desarrollo económico (pp. 29-58). México: Cepal. Disponible en http://www.cepal.org/cgibin/getProd.asp?xml=/publicaciones>.

\section{Declaración de Singapur}

CUHSO adscribe a la Declaración de Singapur sobre la Integridad de la Investigación Científica (disponible en <http://www.singaporestatement.org/Translations/SS_Spanish.pdf>). En ella se establecen principios respecto al cumplimiento de las normativas de investigación, la utilización responsable de métodos de investigación, la difusión pública de resultados, al reconocimiento de autorías intelectuales así como del reconocimiento de personas u organizaciones que han efectuado aportes relevantes para la investigación, el reconocimiento de conflictos de intereses y la valoración de las consecuencias éticas y sociales asociadas al trabajo de investigación, entre otros elementos. Se entiende que la presentación de un artículo a CUHSO implica la aceptación de esta declaración. 